\title{
Factor design methodology for modelling and optimization of carcinogenic acid dye adsorption onto Moroccan prickly pear cactus peel
}

\author{
Rachid Aziam ${ }^{*}$, Latifa Boukarma $^{1}$, Ahmed Zaghloul ${ }^{1}$, Ridouan Benhiti ${ }^{1}$, Elhassane Eddaoudi ${ }^{1}$, Mohamed Zerbet $^{1}$ \\ and Mohamed Chiban ${ }^{1}$
}

${ }^{1}$ LACAPE, Department of Chemistry, Faculty of Science, Ibn Zohr University, Agadir, Morocco

\begin{abstract}
In this study, the modelling and optimization studies of the carcinogenic acid dye sorption from aqueous solutions were carried out using the Factor Design Methodology. This methodology provides a predictive model of the response in the range of variables studied and determines the optimum conditions for the best performance. The sorption of acid dye AB113 on Moroccan prickly pear cactus peel (MPPCP) was chosen as a case study of a typical removal process. Minitab17 software was used to study the effects of adsorption parameters, including initial dye concentration, solution $\mathrm{pH}$, adsorbent dose, contact time, and temperature. Analysis of variance (ANOVA) was used to evaluate the experimental results obtained. The studied parameters at two levels $(-1$ and +1$)$ were coded as $\mathrm{X}_{1}, \mathrm{X}_{2}$, $\mathrm{X}_{3}, \mathrm{X}_{4}$ and $\mathrm{X}_{5}$, consecutively. The optimum conditions obtained for the adsorption of $\mathrm{AB} 113$ dye were: $1 \mathrm{~g}$ for the mass of MPPCP, 6 for the initial solution $\mathrm{pH}, 180 \mathrm{~min}$ for the contact time and $20 \mathrm{mg} / \mathrm{L}$ for the initial dye concentration. The results show that the model is well adapted to the experimental data, indicating the suitability of the model and the success of the factorial design methodology in optimizing the adsorption conditions.
\end{abstract}

\section{Introduction}

Successive use of dyes by the industrial sector poses an aesthetic and sanitary problem because their degradation gives toxic products [1]. Several techniques have been employed for the removal of dyes from industrial effluent including precipitation, coagulation, flocculation, reverse osmosis, filtration, ozonation, and adsorption process [16]. Adsorption is one of the most used for this disposal techniques to treat textile waste effluents because it is easily available, most profitable, easy to operate and most efficient [2]. Several natural biomaterials have been studied for their ability to remove organic pollutants, including coal, newspaper waste, banana peels, orange peels, sawdust, and fly ash [6]. The prickly pear (Opuntia ficus indica) is native to South America, Mexico and the United States, but it grows well in other regions, precisely in Africa and the Mediterranean region [7].

According to Lahsasni et al. [8], prickly pear pulp is characterized by $85 \%$ water, 10 to $15 \%$ carbohydrates and significant amounts of vitamin C, 25 to $30 \mathrm{mg}$ per $100 \mathrm{~g}$ serving. This fruit is also known as "prickly pear", "tuna" and "Indian fig". The total world harvest has been estimated at 300,000 mt of fruit. This study is based on the use of Factor Design Methodology (FDM) as a statistical method for determining optimum conditions. It is a set of statistical and mathematical techniques used for the development and optimization of certain processes in which a response of interest is affected by various process variables in order to optimize this response. The results obtained have been satisfactory in studies involving the application of the factorial design in the adsorption of an anionic dye [9-13].
This study aimed is to determine the optimal experimental conditions for the removal of the AB113 dye by the FDM adsorption technique and to examine the unique and combined effects between the independent variables of contact time, initial dye concentration, adsorbent dose, the temperature and initial solution $\mathrm{pH}$. The influence of certain factors on the removal of the anionic dye AB113 using the dried MPPCP was tested in this work.

\section{Experimental investigation}

\subsection{Reagents and materials}

The synthetic dye used in this study was purchased from Sigma-Aldrich. Acid dye AB113 structure and physicochemical characteristics are presented in Figure 1 and Table 1, respectively. The AB113 Azo Dye Stock Solution containing $500 \mathrm{mg} . \mathrm{L}-1$ has been prepared with doubly distilled water. The working solutions were obtained by diluting the stock solution. The initial $\mathrm{pH}$ value of work solutions was found to be 6.3. The adsorbent used in this study was obtained from Moroccan prickly pear cactus peel (MPPCP). The micro-particles used as bio-adsorbent material in this study without any further pretreatment have a size $<250 \mu \mathrm{m}$ ).

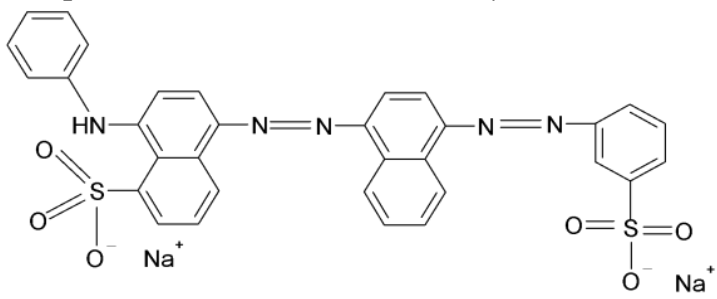

Fig. 1. Molecular structure.

*Corresponding author: rac.aziam@gmail.com 
Table 1. Physicochemical characteristics of acid dye AB113.

\begin{tabular}{|c|c|}
\hline Molecular formula & $\mathrm{C}_{32} \mathrm{H}_{21} \mathrm{~N}_{5} \mathrm{O}_{6} \mathrm{~S}_{2} \mathrm{Na}_{2}$ \\
\hline Chemical Name & Acid blue 113 \\
\hline Chemical class & Anionic, Azo \\
\hline Molar mass & $681.65 \mathrm{~g} / \mathrm{mol}$ \\
\hline Solubility & $40 \mathrm{~g} / \mathrm{L}$ \\
\hline $\begin{array}{l}\text { maximum } \\
\text { wavelength }(\lambda \max )\end{array}$ & $566 \mathrm{~nm}$ \\
\hline Color index number & 26360 \\
\hline Uses & $\begin{array}{l}\text { Used for dyeing wool, nylon } \\
\text { and silk fabric, rayon blended } \\
\text { fabric, and leather; also used } \\
\text { for biological coloring of } \\
\text { paper }\end{array}$ \\
\hline
\end{tabular}

\subsection{Experimental procedure}

In the present investigation, the adsorption experiments were performed in batch mode at room temperature $(23 \pm$ $2{ }^{\circ} \mathrm{C}$ ). Well-established quantities of dried Prickly pear cactus peel (MPPCP) were placed in $100 \mathrm{ml}$ Erlenmeyer glass vials containing $40 \mathrm{ml}$ of AB113 dye solution of known concentration and $\mathrm{pH}$. The solutions were vigorously stirred over a period of time to achieve balance. The stirring rate was kept constant for each pass to ensure an even mixing. After various contact times $(\mathrm{t})$, the resulting solutions were centrifuged at $5000 \mathrm{rpm}$ for $10 \mathrm{~min}$ and the supernatant was filtered and the filtrate analyzed. The determination of the acid dye AB113 was performed by spectrophotometry on a TechComp UV 2300 spectrophotometer at the respective $\lambda \max$ value, which is $566 \mathrm{~nm}$ for AB113. The adsorbed amount of AB113 dye on the micro- particles of the MPPCP bioadsorbent was determined by the difference between the initial concentration and the remaining concentration of the dye solution at time $\mathrm{t}$.

\section{Experimental results and discussion}

\subsection{Adsorption studies}

In order to determine the equilibrium time, equilibrium adsorption experiments were performed using MPPCP with two initial concentrations of the dye $\mathrm{AB} 113$ at $25^{\circ} \mathrm{C}$. The adsorption capacity of the AB113 dye increases with contact time in the first 60 minutes and reaches equilibrium in 90 minutes. In each equilibrium adsorption experiment, 90 minutes was chosen for the MPPCP/AB113 system. The acquired experimental results are illustrated in Figure 2. As shown in this figure, the adsorption process reached the equilibrium in about $90 \mathrm{~min}$. The effect of solution $\mathrm{pH}$ was investigated according to the following procedure. A mass of $0.2 \mathrm{~g}$ of dried MPPCP was added a number of glass bottles containing $40 \mathrm{ml}$ of dye solution.

$0.1 \mathrm{M} \mathrm{HCl}$ or $0.1 \mathrm{M} \mathrm{NaOH}$ solutions were used to adjust the $\mathrm{pH}$ of the $\mathrm{AB} 113$ dye solutions over the range $\mathrm{pH} 2$ to $\mathrm{pH}_{12}$. These results indicate that the removal of the acid dye AB113 is considerably affected by the initial $\mathrm{pH}$ of the solution. According to these results, the adsorption of the acid dye $\mathrm{AB} 113$ first increased slightly from $\mathrm{pH}_{2}$ to $\mathrm{pH}_{8}$ and then decreased from $\mathrm{pH}_{8}$ to $\mathrm{pH}_{12}$. The maximum dye removal for adsorbent was observed at a $\mathrm{pH}$ value of 6 . This significant increase in the retained concentration of AB113 at pH equal to 6 may be due to chemical and electrostatic interactions between the negatively charged surface of the MPPCP adsorbent and the anionic character of AB113 dye [6].

This result showed that $\mathrm{AB} 113$ dye uptake is lower at higher $\mathrm{pH}$ values. The results in Figure 2 show that the adsorption capacity of the dried MPPCP increases with the initial dye concentration of the dye in the solution after 90 minutes contact time. This increase may be due to a higher availability of acid dye molecules, and the active sites of the adsorbent did not reach saturation even at high initial concentrations [6]. This result indicates a high potential for the application of dried particles of MPPCP, as an adsorbent, in the treatment of wastewater containing anionic dyes at high concentrations.
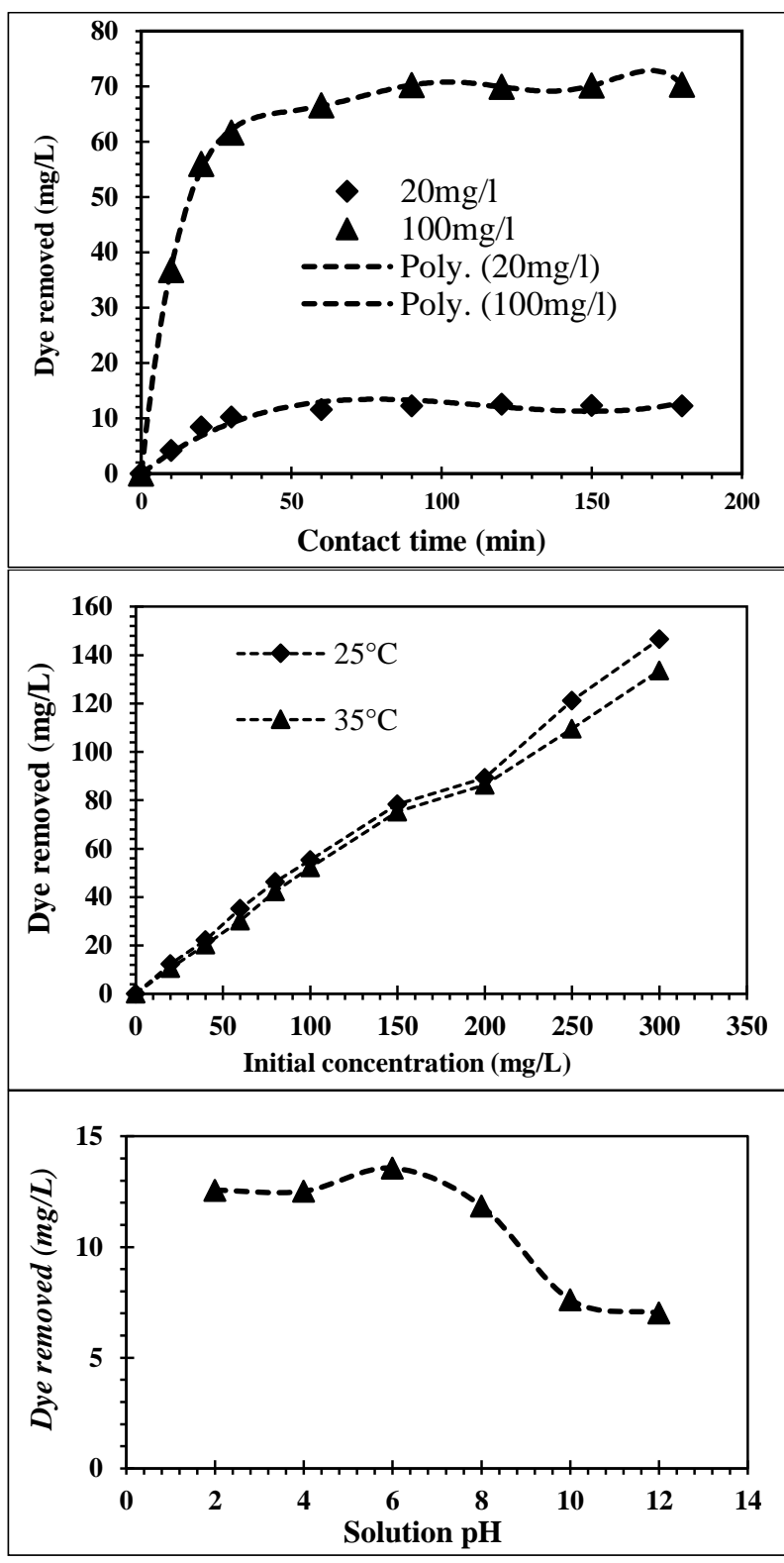

Fig. 2. Factors controlling the adsorption of $A B 113$ dye on MPPCP. 


\subsection{Factorial design methodology model}

In this work, we carried out several preliminary experiments to select the appropriate parameters and determine the field of experimentation. From these experiments, five factors, namely $\mathrm{pH}$ of the solution, mass of the adsorbent, contact time, initial dye concentration and temperature, were selected in this study. The levels of the factors studied are shown in Table 2.

Table 2. Maximum and minimum settings of the factors used in the factorial design model.

\begin{tabular}{cccc}
\hline Factors & Code & $\begin{array}{c}\text { Low } \\
-1\end{array}$ & $\begin{array}{c}\text { High } \\
+1\end{array}$ \\
\hline Temperature $\left({ }^{\circ} \mathrm{C}\right)$ & $\mathrm{X}_{1}$ & 25 & 40 \\
Solution $\mathrm{pH}$ & $\mathrm{X}_{2}$ & 6 & 12 \\
Adsorbent mass $(\mathrm{g})$ & $\mathrm{X}_{3}$ & 0.1 & 1 \\
Initial concentration of & $\mathrm{X}_{4}$ & 20 & 250 \\
AB113 dye (mgL & \\
Contact time $(\mathrm{min})$ & $\mathrm{X}_{5}$ & 5 & 180 \\
\hline
\end{tabular}

The removal percentage of $\mathrm{AB} 113(\mathrm{Y})$ was determined using the following equation:

$$
Y(\%)=\frac{C_{i}-C_{f}}{C i} \times 100
$$

where $\mathrm{Y}(\%)$ is the removal percentage of the $\mathrm{AB} 113$ dye, $\mathrm{C}_{\mathrm{i}}$ and $\mathrm{C}_{\mathrm{f}}$ in $\left(\mathrm{mgL}^{-1}\right)$ are, initial and residual concentrations of the AB113 dye in solution respectively.

In this research, a complete factorial design was used to adapt to a second-order polynomial model. The general equation of the second-degree polynomial is as follows:

$$
Y(\%)=a_{0}+\sum a_{i} x_{i}+\sum a_{i j} x_{i} x_{j}+\sum
$$

where $\mathrm{Y}$ is the dependent variable (response variable) to be modelled, $x_{i}$ and $x_{j}$ are the independent variables (factors), $\mathrm{a}_{0}, \mathrm{a}_{\mathrm{i}}, \mathrm{a}_{\mathrm{ij}}$ are regression coefficients and $\sum$ is the error. The results were analyzed using statistical and graphical analysis software (Minitab 17).

This software was used for regression analysis of the obtained data and to estimate the coefficient of the regression equation.

Analysis of variance, which is a statistical test of the model in the form of linear terms, squared terms and interaction terms, was also used to test the significance of each term in the equation and the quality of fit of the regression model obtained [14].

\subsection{Statistical evaluation}

In order to study the applied influence on the efficiency of AB113 removal by the five selected parameters, various combinations of these parameters were carried out.

The 32 tests representing a complete two-level factorial design for the AB113 azo dye removal are presented in Table 3.
The Design-Minitab17 software planned adsorption experiments according to these variables and their levels.

In order to develop the adsorption process, the empirical experiments necessary to determine the process conditions can be reduced using a practical approach that exploits the known effects of system parameters on the behaviour of the $\mathrm{AB} 113$ dye adsorption by using MPPCP.

The validity of the model is also verified by the analysis of variance (ANOVA) method. This factorial design results in 32 tests with all possible combinations of $\mathrm{x}_{1}, \mathrm{x}_{2}$, $\mathrm{x}_{3}, \mathrm{x}_{4}$ and $\mathrm{x}_{5}$ are given in Table 4.

These response values are obtained by using regression analysis and ANOVA.

Table 3. Experimental matrix for the five factors with two levels of AB113 dye removal using MPPCP.

\begin{tabular}{ccccccc}
\hline Run & \multicolumn{5}{c}{ Coded variables } & \\
\cline { 2 - 5 } & $\mathbf{X}_{\mathbf{1}}$ & $\mathbf{X}_{\mathbf{2}}$ & $\mathbf{X}_{\mathbf{3}}$ & $\mathbf{X}_{\mathbf{4}}$ & $\mathbf{X}_{\mathbf{5}}$ & $\mathbf{Y} \boldsymbol{( \% )}$ \\
\hline 1 & -1 & -1 & -1 & -1 & -1 & 44.32 \\
2 & 1 & -1 & -1 & -1 & -1 & 30.53 \\
3 & -1 & 1 & -1 & -1 & -1 & 16.20 \\
4 & 1 & 1 & -1 & -1 & -1 & 13.73 \\
5 & -1 & -1 & 1 & -1 & -1 & 55.31 \\
6 & 1 & -1 & 1 & -1 & -1 & 50.44 \\
7 & -1 & 1 & 1 & -1 & -1 & 15.32 \\
8 & 1 & 1 & 1 & -1 & -1 & 54.52 \\
9 & -1 & -1 & -1 & 1 & -1 & 8.71 \\
10 & 1 & -1 & -1 & 1 & -1 & 7.32 \\
11 & -1 & 1 & -1 & 1 & -1 & 6.51 \\
12 & 1 & 1 & -1 & 1 & -1 & 6.12 \\
13 & -1 & -1 & 1 & 1 & -1 & 5.59 \\
14 & 1 & -1 & 1 & 1 & -1 & 6.85 \\
15 & -1 & 1 & 1 & 1 & -1 & 6,72 \\
16 & 1 & 1 & 1 & 1 & -1 & 6,49 \\
17 & -1 & -1 & -1 & -1 & 1 & 43.32 \\
18 & 1 & -1 & -1 & -1 & 1 & 35.52 \\
19 & -1 & 1 & -1 & -1 & 1 & 13.41 \\
20 & 1 & 1 & -1 & -1 & 1 & 18.20 \\
21 & -1 & -1 & 1 & -1 & 1 & 82.42 \\
22 & 1 & -1 & 1 & -1 & 1 & 79.83 \\
23 & -1 & 1 & 1 & -1 & 1 & 33.39 \\
24 & 1 & 1 & 1 & -1 & 1 & 22.14 \\
25 & -1 & -1 & -1 & 1 & 1 & 17.61 \\
26 & 1 & -1 & -1 & 1 & 1 & 17.46 \\
27 & -1 & 1 & -1 & 1 & 1 & 7.12 \\
28 & 1 & 1 & -1 & 1 & 1 & 9.05 \\
29 & -1 & -1 & 1 & 1 & 1 & 20.54 \\
30 & 1 & -1 & 1 & 1 & 1 & 19.36 \\
31 & -1 & 1 & 1 & 1 & 1 & 8.15 \\
32 & 1 & 1 & 1 & 1 & 1 & 8.04 \\
\hline & & & & & & \\
& &
\end{tabular}


The removal of the AB113 dye was investigated under various conditions according to the experimental runs. The ANOVA model carried out the analysis of the obtained experimental data. Table 4 shows the ANOVA model data for the AB113 removal percentage (Y \%).

Table 4. Experimental results of 32 factorial design for adsorption of AB113 dye.

\begin{tabular}{|c|c|c|c|c|c|}
\hline Source & VC & DL & SS & Prob. & Sign. \\
\hline Model & - & 25 & 1.35971 & 0.013 & - \\
\hline $\mathrm{a}_{0}$ & 0.2407 & - & - & - & - \\
\hline $\mathrm{a}_{1}$ & 0.0003 & 1 & 0.00000 & 0.986 & Yes \\
\hline $\mathrm{a}_{2}$ & -0.0875 & 1 & 0.24504 & 0.002 & Yes \\
\hline $\mathrm{a}_{3}$ & 0.0562 & 1 & 0.10123 & 0.013 & Yes \\
\hline $\mathrm{a}_{4}$ & -0.1397 & 1 & 0.62429 & $<0.001$ & - \\
\hline $\mathrm{a}_{5}$ & 0.0315 & 1 & 0.03180 & 0,096 & - \\
\hline $\mathrm{a}_{12}$ & 0.0194 & 1 & 0.01200 & 0.272 & - \\
\hline $\mathrm{a}_{13}$ & 0.0123 & 1 & 0.00888 & 0.470 & - \\
\hline $\mathrm{a}_{14}$ & -0.0005 & 1 & 0.00001 & 0.978 & - \\
\hline $\mathrm{a}_{15}$ & -0.0105 & 1 & 0.00354 & 0.535 & - \\
\hline $\mathrm{a}_{23}$ & -0.0160 & 1 & 0.00817 & 0.357 & Yes \\
\hline $\mathrm{a}_{24}$ & 0.0592 & 1 & 0.11227 & 0.010 & Yes \\
\hline $\mathrm{a}_{25}$ & -0.0353 & 1 & 0.03997 & 0.069 & Yes \\
\hline $\mathrm{a}_{34}$ & -0.0551 & 1 & 0.09713 & 0.014 & - \\
\hline $\mathrm{a}_{35}$ & 0.0139 & 1 & 0.00615 & 0.419 & - \\
\hline $\mathrm{a}_{45}$ & 0.0016 & 1 & 0.00008 & 0.923 & - \\
\hline $\mathrm{a}_{123}$ & 0.0025 & 1 & 0.00020 & 0.881 & - \\
\hline $\mathrm{a}_{124}$ & -0.0177 & 1 & 0.01003 & 0.311 & - \\
\hline $\mathrm{a}_{125}$ & -0.0149 & 1 & 0.00715 & 0.386 & - \\
\hline $\mathrm{a}_{134}$ & -0.0125 & 1 & 0.00501 & 0.464 & - \\
\hline $\mathrm{a}_{135}$ & -0.0210 & 1 & 0.01415 & 0.237 & - \\
\hline $\mathrm{a}_{145}$ & 0.0113 & 1 & 0.00409 & 0.506 & - \\
\hline $\mathrm{a}_{234}$ & 0.0156 & 1 & 0.00776 & 0.368 & - \\
\hline $\mathrm{a}_{235}$ & -0.0242 & 1 & 0.01876 & 0.181 & - \\
\hline $\mathrm{a}_{245}$ & 0.0104 & 1 & 0.00343 & 0.541 & - \\
\hline $\mathrm{a}_{345}$ & -0.0090 & 1 & 0.00257 & 0.596 & - \\
\hline VC $:$ values of the coefficients & & \\
\hline DL $:$ Degrees of liberty & & & \\
\hline SS : Sum of squares & & & \\
\hline Sign. : signification & & & \\
\hline & & & & & \\
\hline
\end{tabular}

As can be seen in Table 4, P-value less than 0.05 demonstrates that these model terms are important. A first-order model with all possible types of interactions was selected to adapt to the experimental model:

Removal percentage $(\%)=0,2407+0,0003 X_{1}-0,0875$ $\mathrm{X}_{2}+0,0562 \mathrm{X}_{3}-0,1397 \mathrm{X}_{4}+0,0315 \mathrm{X}_{5}+0,0194 \mathrm{X}_{12}+$ $0,0123 X_{13^{-}} 0,0005 X_{14^{-}} 0,0105 X_{15^{-}} 0,0160 X_{23}+0,0592$ $\mathrm{X}_{24^{-}} 0,0353 \mathrm{X}_{25^{-}} 0,0551 \mathrm{X}_{34}+0,0139 \mathrm{X}_{35}+0,0016 \mathrm{X}_{45}+$ $0,0025 X_{123^{-}} 0,0177 X_{124-} 0,0149 X_{125^{-}} 0,0125 X_{134}-$ $0,0210 X_{135}+0,0113 X_{145}+0,0156 X_{234-} 0,0242 X_{235}+$ $0,0104 X_{245-0} 0,0090 X_{345}$

Therefore, the determination coefficient can indicate the signification of the regression model. The $\mathrm{R}^{2}$ value is always between 0 and 1 . The closer the $R^{2}$ value is to 1 , the better the model predicts the response [15].
The determination coefficient $\mathrm{R}^{2}$ is equal to 0.9651 , which means that the regression model is significant at $96.51 \%$ of the degree of confidence, i.e. the model allows $95.12 \%$ of the measured responses to be found.

\subsection{Sensitivity Analysis}

To study the individual and interactive effect of these five factors on the efficiency of AB113 dye removal. The effects of the factors studied on the removal percentage of AB113 dye can be represented graphically as shown in Fig.3.

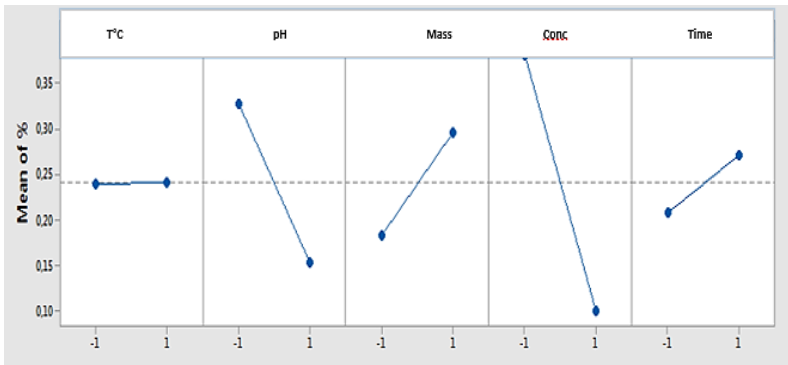

Fig. 3. Effect of the factors studied

As seen from Figure 3, the results show that adsorbent mass, solution $\mathrm{pH}$ and initial dye concentration are the main factors that have the greatest influence on the removal efficiency of the $\mathrm{AB} 113$ dye.
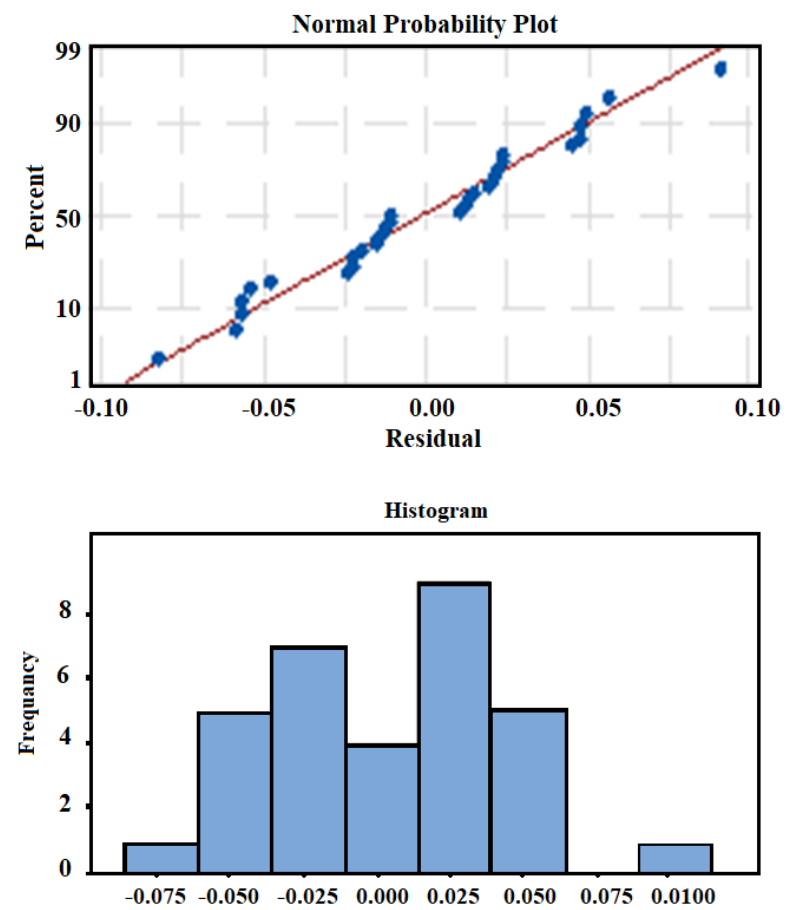

Fig. 4. Residual plots for removal percentage of AB113.

The decrease in $\mathrm{pH}$ leads to a good removal percentage yield, the removal percentage is inversely proportional to the $\mathrm{pH}$, which explains why the good elimination yield is obtained for the lowest $\mathrm{pH}$ values. For the MPPCP / AB113 system, we observed that the initial concentration has a very important influence on the adsorption yield, which expresses the impact of concentration on the process. On the other hand we see that the mass and the contact time have an average effect, but the temperature 
has no effect. Figure 4 shows the residual value and the order of the corresponding observations. This diagram can be useful for an experiment designed in which the runs are not randomized. In the case of residual activity data, the residuals appear to be randomly dispersed around zero. No evidence of non-constant variance, missing conditions or influence points exists. The normal probability plot indicates that the residuals appear normally distributed in a straight line, which proves that the values obtained are normal, symmetrical and that there are no abnormal values [16].

\section{Conclusion}

The experimental design used in this study allows a rigorous analysis of the factors influencing the removal of AB113 dye using adsorption process. Optimal conditions obtained by a statistical method have been successfully determined to maximize the removal of AB113 dye.

The model predicted that the temperature, $\mathrm{pH}$ of the solution, adsorbent mass and contact time are the factors that have the greatest influence on the removal efficiency of the AB113 dye by using MPPCP.

The optimum conditions obtained by factorial design methodology model for the adsorption of AB113 dye were: $1 \mathrm{~g}$ for the mass of MPPCP, 6 for the initial solution $\mathrm{pH}, 180 \mathrm{~min}$ for the contact time and $20 \mathrm{mg} / \mathrm{L}$ for the initial dye concentration.

The results show that the model is well adapted to the experimental data, indicating the suitability of the model and the success of the factorial design methodology in optimizing the adsorption conditions. The high correlation of the model with the experimental results indicates that FDM analytical procedure could be a general method to describe the adsorption process.

The results show that the model is well adapted to the experimental data, indicating the suitability of the model and the success of the factorial design methodology (FDM) in optimizing the adsorption conditions.

The experimental results of batch adsorption showed and confirmed the elimination of AB113 dye by the MPPCP.

The effects of parameters such as adsorbent mass, contact time, initial dye concentration, solution $\mathrm{pH}$ and temperature on the removal of the azo dye AB113 by dried MPPCP micro-particles were studied.

The effect of $\mathrm{pH}$ on the adsorption of the azo dye AB113 showed that the adsorption capacity of the AB113 dye increases from $\mathrm{pH}_{2}$ to $\mathrm{pH}$.
The maximum dye removal for adsorbent was observed at a $\mathrm{pH}$ value of 6 . Best removal efficiency and maximum adsorption capacity of AB113 dye was achieved after a contact time of $90 \mathrm{~min}$. Finally, excellent regenerative efficacy of the adsorbent MPPCP contributes a significant achievement toward sustainable development in dye contaminated wastewater treatment.

\section{References}

1. H.M Saleh, H.R. Moussa, F.A. El-Saied, M. Dawoud, A.N. El Said, R.S. Abdel Wahed, Prog. Nucl. Energy, 125, 103393 (2020)

2. R. Aziam, M. Chiban, H. Eddaoudi, A. Soudani, M. Zerbet, F. Sinan, The Eur. Phys. J. Special Topics 226, 977-992 (2017)

3. M. Ghaedi, B. Sadeghian, A.A. Pebdani, R. Sahraei, A. Daneshfar, C. Duran, Chem. Eng. J, 187, 133-141 (2012)

4. M. Chiban, A. Soudani, M. Zerbet, and F. Sinan, Nova Science Publishers, USA, 249-262 (2013)

5. VK. Gupta, Suhas, I. Tyagi, S. Agarwal, R. Singh, M. Chaudhary, A. Harit, S. Kushwaha, Global J. Environ. Sci. Manag, 2, 1-10 (2016)

6. R. Aziam, E. Eddaoudi, A. Soudani, M. Zerbet, F. Sinan, M. Chiban, Arab. J. Geosci, 9, 659 (2016)

7. S. Lahsasni, M. Kouhila, M. Mahrouz, Energy Convers. Manag, 45, 249-261 (2004)

8. S. Lahsasni, M. Kouhila, M. Mahrouz, N. Kechaou, J. Food Eng, 55, 201-207 (2002)

9. M.A. Rauf, N. Marzouki and B.K. Kbahti, J. Hazard. Mater 159, 602-609 (2008)

10. I.H. Cho and K.D. Zoh, Dyes Pigm. 75, 533-543 (2007)

11. N. Barka, M. Abdennouri, A. Boussaoud, A. Galadi, M. Baâlala, M. Bensitel, A. Sahibed-Dine, K. Nohair and M. Sadiq, Arab. J. Chem, 7, 752-757 (2011)

12. A.R. Khataee, M.B. Kasiri and L. Alidokht, Environ. Technol, 32, 1669-1684 (2011)

13. A. Abaamrane, S. Qourzal, N. Barka, S. Mançour Billah, A. Assabbane, Y. Ait-Ichou, Orient. J. Chem, 28, 1091-1098 (2012)

14. Li. Huiping, G. Zhao, S Niu and Y. Luan, Comput. Mater. Sci, 38, 561-570 (2007)

15. J.F Fu, Y.Q Zhao and Q.L. Wu, J. Hazard. Mater, 144, 499-505 (2007)

16. A. Abaamrane, S. Qourzal, M. El Ouardi, S. Alahiane, M. Belmouden, Bari H, Barka N,S. Mançour Billah, A. Assabbane, Y. Ait-Ichou, Desalin. Water. Treat, 53, 249-256 (2015) 